\title{
Metodologia para determinar la calidad del agua a partir de métodos analíticos sensoriales
}

\section{Methodologic to determine the water quality trough sensory analytical methods}

\section{Jeniffer K Carrillo Gי; Cristhian M Duran A²}

1. MsC. Grupo GISM, Facultad de ingenierías y arquitectura, Universidad de Pamplona jenifferk_1206@hotmail.com

2 PhD Grupo GISM, Facultad de ingenierías y arquitectura, Universidad de Pamplona cmduran@unipamplona.edu.co

\section{Resumen}

La presente metodología tiene como finalidad desarrollar e implementar un equipo muestreador "Headspace" estático para extraer diferentes compuestos orgánicos volátiles (COV's) de muestras de agua contaminada por bacterias. Para probar el sistema de extracción se realizaron diferentes medidas con agua potable y contaminada en rangos de temperaturas entre $60^{\circ} \mathrm{C}$ y $90^{\circ} \mathrm{C}$ con el fin de obtener un patrón característico de cada compuesto. Para analizar las muestras se utilizó un sistema sensorial compuesto por una matriz de seis sensores de óxidos metálicos previamente seleccionados. La cámara de sensores fue acoplada al equipo de extracción para la detección de los analitos. Los resultados preliminares obtenidos, demostraron que el sistema de extracción estático acoplado a un equipo sensorial es capaz de generar una huella del COV para ser utilizado como método alternativo para el control de calidad del agua.

Palabras clave: COV', headspace, microorganismos, sensores de gases.

\begin{abstract}
The purpose of this methodology it is to develop and implement a static "Headspace" sampler equipment to extract a set of volatile organic compounds (VOC's) from water samples contaminated by bacteria. For testing the extraction system different measurements with potable and contaminated water were made, with temperature range around $60^{\circ} \mathrm{C}$ and $90^{\circ} \mathrm{C}$, in order to obtain a characteristic pattern of each compound. For analyzing the samples, a sensorial system composed of six metal oxide gas sensors was used, which were selected previously. The sensor chamber was coupled to the extraction equipment for analyte detection. The preliminary results obtained, demonstrated that the static extraction system methods coupled to a sensory system, it is capable to generate a fingerprint of VOC, to be used as an alternative method for water control quality.

Keywords: VOC's, headspace, microorganisms, gas sensors.
\end{abstract}


186

\section{Introducción}

La Organización Mundial de la Salud (OMS) en las guías para la calidad del agua potable, establece la ausencia de cualquier microorganismo en el agua potable para consumo humano que pueda afectar la salud del consumidor, este parámetro es utilizado como guía de calidad del agua para la creación de reglamentos o normas, también sirve para evaluar los riesgos de contaminación, vigilar los procesos de tratamiento y hacer planes correctivos para alcanzar la calidad deseada ${ }^{1}$. En Colombia la calidad microbiológica solo incluye el control de bacterias como coliformes totales y fecales. La E. Coli es una bacteria elegida como indicador de contaminación fecal y es importante en la verificación de la calidad microbiológica del agua ${ }^{1,2}$.

Para la detección de contaminantes microbiológicos en agua se usan técnicas convencionales en cultivos como: Fermentación de tubos múltiples, filtración por membrana, enzima sustrato, sustrato definido y presenciaausencia de microorganismos, estos son los métodos reconocidos en Colombia y normalizados en la resolución número: 2115 "Características, instrumentos básicos y frecuencias del sistema de control y vigilancia para la calidad del agua para consumo humano" 3 .

La cromatografía de gases y la espectrometría de masas también son técnicas muy usadas para identificar los microorganismos a través del análisis de los compuestos orgánicos volátiles que estos generan como parte de su metabolito normal ${ }^{4}$ y que son específicos para cada especie, por ejemplo, la producción de indol (Escherichia coli), sulfuro de hidrógeno (Proteus y Citrobacter spp.), y trimetilamina (E. coli y Enterobacter spp $)^{5,6}$. Los beneficios potenciales de los métodos analíticos en los laboratorios han sido reconocidos por mucho tiempo a través de la historia, pero ninguno de estos métodos puede cumplir completamente con los requisitos de tiempo, sensibilidad y precisión, adicionalmente son técnicas muy laboriosas, requieren de instalaciones, equipos, insumos, personal capacitado, $y$ no son muy eficientes para las aplicaciones de monitoreo en el sitio.

Para un monitoreo continuo, con tiempos de respuesta rápido y bajo costo, se han desarrollado nuevas técnicas usando un sistema multisensorial (olfato electrónico) compuesto por un conjunto de sensores de gases químicos con sensibilidades parcialmente solapadas. Dentro de los subsistemas del equipo multisensorial se encuentra la etapa de acondicionamiento de la muestra, por lo tanto, es importante preparar la muestra con las condiciones adecuadas con el objetivo de que los sensores de gases tengan buena sensibilidad y selectividad a la hora de detectar los compuestos orgánicos volátiles. Uno de los problemas frecuentes en los sistemas de olfato electrónico es la sensibilidad y selectividad, ya que la mayoría de las 
187

veces la muestra no llega en las mejores condiciones a la cámara de medición, por tal motivo se hace necesario mejorar la etapa de muestreo en estos equipos de medida. Es por eso que en este estudio hemos desarrollado una metodología compuesta por un sistema de extracción de espacio de cabeza que pueda ser integrado a un equipo multisensorial con el objetivo de detectar un conjunto de bacterias producidas en el agua a muy bajas concentraciones.

\section{Metodología}

La Figura 1 muestra cada uno de los pasos para el desarrollo de la metodología propuesta.

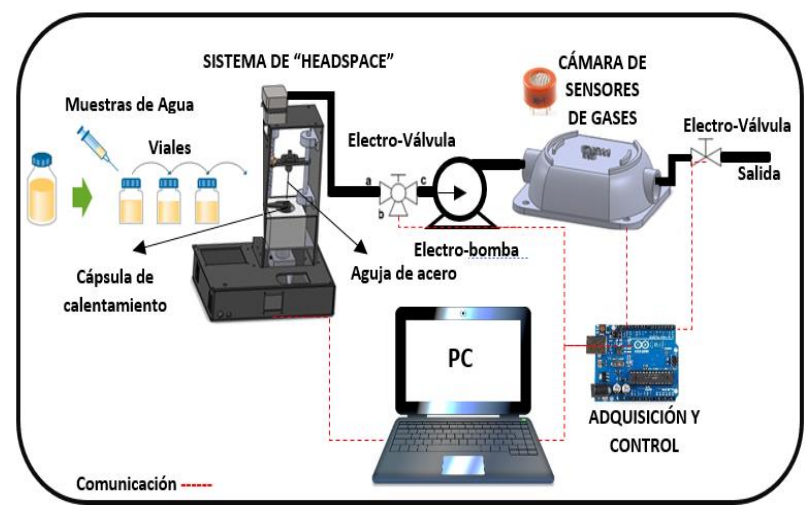

Figura 1. Metodología

2.1 Diseño del muestreador de espacio de cabeza automático para extraer los COV's

En esta etapa se utiliza un mecanismo de extracción automática compuesto por:

\subsubsection{Una resistencia calefactora:}

Consta de un sensor de temperatura (termocuplas) y circuito de acondicionamiento de la señal
(MAX6675) para el diseño de un control Proporcional, Integral Derivativo (PID) de temperatura.

Dentro de la resistencia se coloca un vial de $25 \mathrm{~mL}$, el cual contiene la muestra a analizar, estos se mantienen a condiciones de temperatura y tiempo controlado para permitir que los compuestos volátiles orgánicos pasen de la fase liquida a la fase gaseosa para ser transferidos al sistema de olfato electrónico.

\subsubsection{Un sistema de invección automático con una aguja en acero inoxidable}

Cuando el tiempo de calentamiento programado se cumpla, la jeringa se desplaza a través de un sistema mecánico automatizado para realizar el movimiento en el eje $Z$ penetrando la jeringa al vial y extrayendo los compuestos volátiles generados por la muestra. A su vez, con una bomba de vacío se transportan los COV's mediante un sistema de tuberías fabricadas en acero inoxidable flexible hacia la cámara de sensores, para el análisis e identificación.

\subsection{Diseño de la cámara de sensores}

La cámara de sensores se diseñó con un bajo volumen muerto con el objetivo de obtener una mayor sensibilidad de los sensores de gases. Se usaron sensores de gases, Ref: MQ previamente seleccionados de acuerdo a la revisión de las hojas de datos relacionada con el tema. 
188

En la tabla 1 se describe el tipo de sensor y las aplicaciones de cada uno de ellos.

Tabla 1. Sensores de gases de óxidos metálicos

\begin{tabular}{|c|l|}
\hline Sensores & \multicolumn{1}{|c|}{ Gases de medición } \\
\hline MQ2 & Metano, butano, GLP, humo \\
\hline MQ3 & Alcohol, Etanol, Humo \\
\hline MQ9 & $\begin{array}{l}\text { Monóxido de carbono, gas } \\
\text { combustible }\end{array}$ \\
\hline MQ135 & $\begin{array}{l}\text { Benceno, alcohol, humo, } \\
\text { calidad del aire }\end{array}$ \\
\hline MQ 136 & Sulfuro de Hidrógeno \\
\hline MQ 138 & $\begin{array}{l}\text { Benceno, Tolueno, Alcohol, } \\
\text { Formaldehido Propano, }\end{array}$ \\
\hline
\end{tabular}

\subsection{Recolección acondicionamiento de las muestras.}

Las muestras de agua se recolectan de las plantas de tratamiento de agua potable. Para esta metodología se escogen dos tipos de bacterias Escherichia Coli y Pseudomonas Aeruginosa que se encuentran con gran frecuencia en las fuentes de agua. Para el acondicionamiento es necesario preparar un conjunto de muestras control:

Control negativo: Consiste en una muestra de agua que es llevada a una autoclave por un tiempo de 15 minutos a una temperatura de $121,1^{\circ} \mathrm{C}$, con el fin de obtener una muestra estéril que esté libre de cualquier microrganismo.

Control positivo: Se usa agua previamente esterilizada (como en el control negativo), inoculada con Escherichia coli (cepa ATCC 25922). Esta inoculación consiste en la adición de determinada cantidad de bacterias viables al agua estéril. La cuantificación del inóculo se realizará teniendo en cuenta los estándares de turbidez de McFarland, el cual nos sirve como referencia para determinar la cantidad de bacterias que hay en la suspensión microbiana. Específicamente se usará como referencia el patrón $\mathrm{N}^{\circ} 1$ que equivale a $3 \times 10^{8}$ bacterias.

Control de especificidad: Con el fin de estimar la especificidad de la detección, se preparan muestras de agua estéril contaminadas de manera controlada con la bacteria Pseudomona aeruginosa (ATCC 27853), de la misma manera que lo descrito para el control positivo. P. aeruginosa es una bacteria que pertenece a la misma clase, pero a un orden taxonómico diferente al de $\mathrm{E}$. coli (no es una bacteria coliforme); adicionalmente, es una especie bacteriana muy frecuente en aguas, por lo que es muy útil su uso como cepa contraste para evaluar la especificidad de la detección.

\subsection{Realización de medidas.}

Una vez diseñado el muestreador y acoplado a la cámara de medición se realiza las diferentes medidas a partir de las muestras previamente acondicionadas con el objetivo del 
189

entrenamiento del sistema multisensorial y de verificar la especificidad, sensibilidad y selectividad del sistema de medición.

\subsubsection{Especificidad}

El sistema multisensorial es probado con las muestras acondicionadas. Para ello se usa el control negativo, el control positivo y los controles de especificidad (cuya preparación ya fue descrita). Cada muestra es adicionada dentro de un vial de $25 \mathrm{~mL}$, el cual se coloca dentro de la capsula calefactora del sistema de extracción de espacio de cabeza estático, para generar los COV's. Para obtener estos compuestos se programan varios niveles de temperaturas y tiempos de incubación:

- La muestra es calentada a $37^{\circ} \mathrm{C}$ durante 15 minutos, la cual es la temperatura optima de crecimiento de la E. Coli y Pseudomonas aeruginosa. Con el objetivo de mejorar el enriquecimiento de los compuestos generados se aumenta la temperatura hasta $70{ }^{\circ} \mathrm{C}$, durante un tiempo de 10 minutos.

- Una vez trascurrido el tiempo y se haya alcanzado la temperatura deseada se procede a hacer la extracción de los compuestos volátiles orgánicos, que son transportados con una bomba al vacío hasta la cámara de sensores para el respectivo análisis. Los datos obtenidos son procesados y usados para la discriminación de las muestras mediante técnicas de reconocimiento de patrones. Cabe resaltar que la especificidad representa la probabilidad de que una muestra de agua sin contaminación tenga un resultado negativo en la prueba, es decir, que los verdaderos negativos, sean catalogados siempre como negativos por el sistema.

Para optimizar el funcionamiento del equipo se hacen varios ensayos modificando la segunda temperatura a 80 y $100{ }^{\circ} \mathrm{C}$.

\subsubsection{Sensibilidad}

Para evaluar la sensibilidad del sistema multisensorial, se realizan diluciones del control positivo para disminuir progresivamente la población bacteriana en suspensión, con el fin de estimar la población bacteriana más pequeña que el sistema es capaz de detectar. Es decir, con esto se busca determinar la capacidad del mecanismo para detectar la bacteria (E. coli) en bajas concentraciones.

\subsection{Adquisición de medidas, análisis y procesado de datos.}

La matriz de sensores que hacen parte de la cámara de medición, transforman las reacciones químicas en señales eléctricas adquiriendo la información y extrayendo rasgos característicos de la muestra examinada. A través de métodos de reconocimiento de patrones tales como: Análisis de Componentes Principales (PCA), análisis de función de discriminantes (DFA), análisis de clusters $(\mathrm{CA})$, redes neuronales 0 inteligencia artificial, se discriminan y clasifican los compuestos generados desde las diferentes muestras.

\subsection{Validación del sistema}

Para validar los resultados obtenidos se usan los métodos convencionales, 
190

cromatografía de gases con espectrometría de masas y análisis electroquímicos (e-tongue).

Cabe mencionar que, para el análisis de las muestras con los diferentes métodos, se debe usar la misma muestra de agua. Se espera que el resultado obtenido por el sistema en general sea similar o aproximado a los demás métodos.

\section{Resultados}

Para observar la efectividad del equipo de extracción mediante las respuestas de los sensores de gases, se colocaron muestras de agua a una temperatura de $70{ }^{\circ} \mathrm{C}$.

A través de una interfaz de usuario gráfica, se programaron los tiempos de extracción y adquisición de las señales de los sensores, donde el tiempo de calentamiento de la muestra fueron 5 minutos y de adquisición fueron 3 minutos. Para la recuperación o purga de los sensores se utilizó un nebulizador eléctrico con el fin de evacuar los COV's adquiridos en la medición.

La Figura 2 ilustra el comportamiento de los sensores de gases en el momento en que se extraen los COV's. Se puede observar una buena sensibilidad en cada uno de ellos, ante la extracción de la muestra de agua potable y a su vez una rápida recuperación.

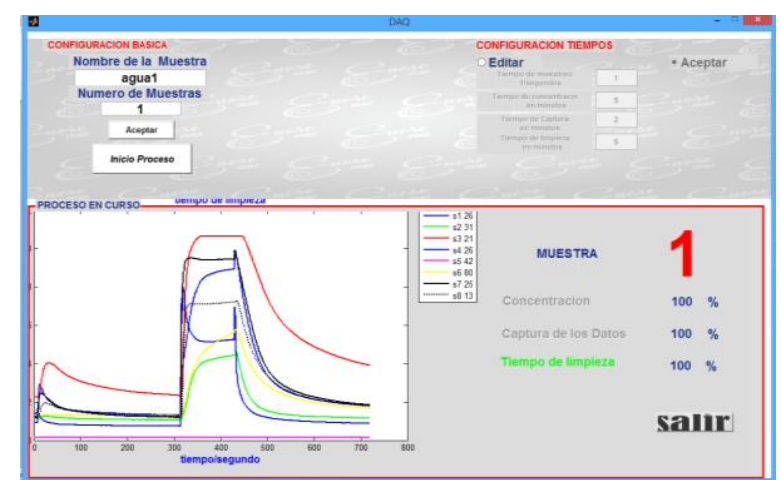

Figura 2. Respuesta de los sensores para una muestra de Agua potable a $70^{\circ} \mathrm{C}$

Por otro lado, en la Figura 3 se muestra el comportamiento de los sensores ante la extracción de la muestra de agua contaminada. Se puede observar que la amplitud de las señales es mayor en este caso, en comparación con el análisis de la muestra de agua potable. Lo anterior es debido a que existen mayor cantidad de compuestos en altas concentraciones en la muestra contaminada.

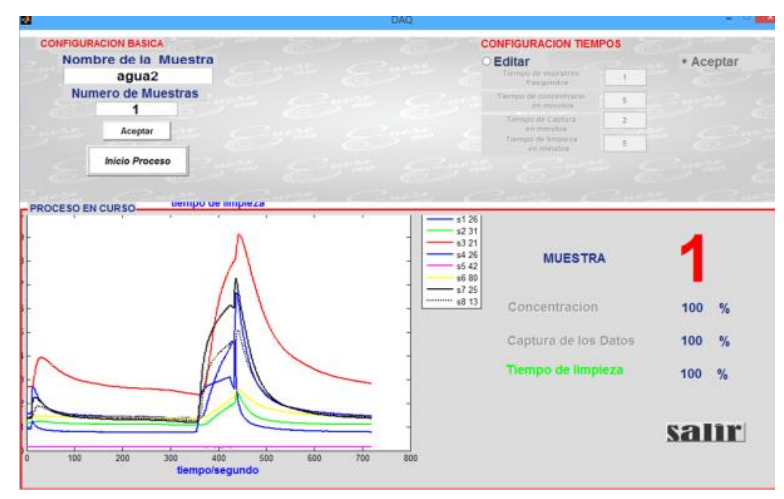

Figura 3. Respuesta de los sensores para una muestra de Agua contaminada a $70^{\circ} \mathrm{C}$

\section{Conclusiones}

Con el desarrollo de la metodología propuesta es posible determinar de forma rápida, bajo costo y portabilidad con el fin de detectar el grado de contaminación en 
191

muestras de agua para evaluar su calidad. A través de los componentes tecnológicos utilizados en este estudio y los resultados obtenidos, es prometedor implementar este sistema de extracción sensorial en diferentes aplicaciones (alimentos, salud, ambiental, entre otros).

En la segunda fase de este estudio se pretende realizar pruebas con diferentes tipos de muestras de agua contaminada con bacterias como Escherichia Coli, Pseudomonas Aeruginosa, salmonella entre otras, con el fin de evaluar el funcionamiento.

\section{Agradecimientos}

Se agradece la colaboración de los ingenieros electrónicos Emily Trujillo y Jorge Portilla, los cuales dieron soporte al diseño y desarrollo del equipo de extracción.

\section{Referencias Bibliogràfícas}

1. Organizacion mundial de la salud. Guías para la calidad del agua potable (2006). Recuperado http://www. who.int/water sanitat ion health/dwa/gdwq3 es fulll lo wsres.pdf

2. Edberg. S.C, E.W. Rice, R.J. Karlin \& M.J. Allen. (2012). Escherichia coli: the best biological drinking water indicator for public health protection. Revista Journal of Applied Microbiology, 88: 106S$116 S$. https://doi.org/10.1111/j.1365-

2672.2000.tb05338.x

3. Ministerio de la protección social ministerio de ambiente, vivienda y desarrollo territorial. (22 de junio de 2007). características, instrumentos básicos y frecuencias del sistema de control y vigilancia para la calidad del agua para consumo humano. [Resolucion 2115]/Recuperado de http://www.minambiente.gov.co/i mages/GestionIntegraldelRecurso Hidrico/pdf/normativa/Res_2115_ de_2007.pdf

4. Lieuwe D. J, Peter J. Sterk \& Marcus J. Schultz. (2013). Volatile Metabolites of Pathogens: A Systematic Review. Revista PLOS Pathogens, 9(5): e1003311. doi:10.1371/journal.ppat.1003311

5. Robin S.T, Darren M.R \& John G. (2011). Multivariate analysis of bacterial volatile compound profiles for discrimination between selected species and strains in vitro. Revista Journal of Microbiological Methods, 84, 258264. doi:

10.1016/j.mimet.2010.12.001. Epub 2010 Dec 16.

6. Zulkifli, S.Z, Rahim, H.A \& Lau, W.J. (2017). Detection of contaminants in water supply: A review on state-of-the-art 
192

monitoring technologies and their applications Syahidah. Revista Sensors and Actuators $B$ : Chemical. 255: 2657-2689. DOI10.1016/j.snb.2017.09.078

7. Nelson Fernández, Alberto Ramírez, Fredy Solano.2013.Dinámica Fisicoquímica y Calidad del Agua en la Microcuenca el Volcan, Municipio de Pamplona, Colombia. Bistua: Revista de la facultad de Ciencias Basicas.3(1):5-17

J.K. Carrillo Gomez, Ingeniera Química de la Universidad de Pamplona - UP; MsC magister en controles industriales de la Universidad de Pamplona, Pamplona; Integrante activo del Grupo de Investigaciones sistemas multisensoriales y reconocimiento de patrones (GISM), código orcid: https://orcid.org/00000002-0659-9988.

C.M. Duran Acevedo, Ingeniero electrónico de la Universidad de Pamplona- UP; PhD ingeniería electrónica de la Rovira i virgili de Tarragona, España; Docente titular tiempo completo, Coordinador del grupo de investigación de sistemas multisensoriales y reconocimiento de patrones (GISM), código orcid: https://orcid.org/00000002-5241-2950.

*Para citar este artículo: Carrillo G.J.K; Duran A C.M. Methodologic to determine the water quality trough sensory analytical methods.Revista Bistua.2018.16(1):185-
192.

+ Autor para el envió de correspondencia y la solicitud de las separatas: Carrillo G.J.K MsC . Grupo GISM, Facultad de ingenierías y arquitectura, Universidad de Pamplona jenifferk_1206@hotmail.com

Recibido: Enero 30 de 2018

Aceptado: Marzo 15 de 2018 